\title{
DE LA PRODUCCIÓN DE ÁNFORAS DE SALAZÓN EN LA BAHÍA DE CÁDIZ. MATERIALES DEL ALFAR DE «EL OLIVAR DE LOS VALENCIANOS», PUERTO REAL
}

POR

\author{
ALBERTO CAMPANO LORENZO \\ Departamento de Prehistoria y Arqueologia. Universidad de Valladolid.
}

\begin{abstract}
RESUMEN
En este articulo se plantea una discusión acerca del contexto económico del horno de ánforas de salazón de «El Olivar de los Valencianos», en Puerto Real (C'ádiz), sosteniendo que este alfar responde a un modelo similar al de los hornos hispanos de ánforas de vino y aceite contemporáneos y cuestionando, por tanto, el esquema económico propuesto para explicar la concentración de restos anfóricos en la bahia de Cádiz.
\end{abstract}

\section{SUMMARY}

This paper poses a discussion about the economic context of the fish-based products amphorae kiln of «El Olivar de los Valencianos", in Puerto Real, Cádiz, supporting that this kiln worked in an analogous way as the contemporaneous Spanish kilns of wine and oil amphorae, so arguing about the economical model prevailing to explain the abundance of amphorae waste in the bay of Cádiz.

El Olivar de los Valencianos es el nombre de una finca situada al este del núcleo urbano de Puerto Real, Cádiz. Parte de ella está ocupada por un yacimiento arqueológico, delatado en superficie por abundantísimos fragmentos anfóricos, concentrados principalmente sobre la cumbre y ladera sur de una suave loma alargada que domina el entorno inmediato.

El enclave fue excavado a mediados de este siglo por María Josefa Jiménez Cisneros ' , quien exhumó la estructura que nos ocupa. Recientemente,

\footnotetext{
' Jiménez exhumó un horno de planta circular, dotado de una parrilla radial "en perfecto estado", con el laboratorio conservado hasta "el borde del arranque de la bóveda" y abierto a un corredor (Jiménez, 1971, 146-147). Parece ser que el conjunto arquitectónico quedó desde entonces a la intemperie, expuesto a la actuación reiterada de buscadores clandestinos, en parte paliada por alguna intervención arqueológica posterior. En 1980 se acometió una nueva excavación arqueológica que permitió do-
}

$y$ ante la buena disposición del propietario del terreno, el Área de Cultura del Ayuntamiento de Puerto Real decidió promover una excavación arqueológica en el horno para documentar su grado de conservación de cara a un posible acondicionamiento para su visita pública ${ }^{2}$. Merced a esta iniciativa, quedó exhumado el conjunto que viera Jiménez, formado por tres estructuras (fig. 1). En primer término, un espacio definido por dos paredes convergentes hacia la entrada de un corredor (ante el desconocimiento de sus funciones y atendiendo a su carácter de ámbito de acceso al horno, lo denominamos (atrio»). Este corredor, que constituye la segunda estructura, da paso a un laboratorio de planta circular, cuyo alzado oscila entre 1,5 y $1,8 \mathrm{~m}$, solado por una parrilla de estructura radial casi completa, cuya cara interna, en forma de bóveda anular, sirve de techo a la cámara de combustión, entonces colmatada por sedimentos (fig. 2).

Durante la excavación constatamos la génesis reciente de la práctica totalidad de las unidades estratigráficas (UU.EE. en adelante) no constructi-

cumentar la existencia de dos hornos más, semejantes al anterior, y señalar las ánforas Beltrán IIA como uno de los productos del al far (López, 1981). Queremos aprovechar la ocasión que nos brindan estas lineas para agradecer a María Dolores López de la Orden, directora de esa campaña, las facilidades y el apoyo prestados a nuestro trabajo.

${ }_{2}^{2}$ Para acometer dicha actuación arqueológica, el Área de Cultura del Ayuntamiento de Puerto Real entró en contacto con nuestro equipo arqueológico, integrado por Mercedes Gallardo Abarzuza, Josefa Marti Solano y el autor de estas lineas, y con el arqueólogo de la Delegación Provincial de Cádiz, de la Consejeria de Cultura y Medio Ambiente de la Junta de Andalucia, Lorenzo Perdigones Moreno, quien tramitó el permiso y fijó las directrices de la excavación, que consistieron en ureexcavar lo excavado", limitándonos siempre al interior de la estructura. Su apoyo fue esencial durante buena parte del trabajo de campo y le expresamos nuestro agradecimiento por ello. 


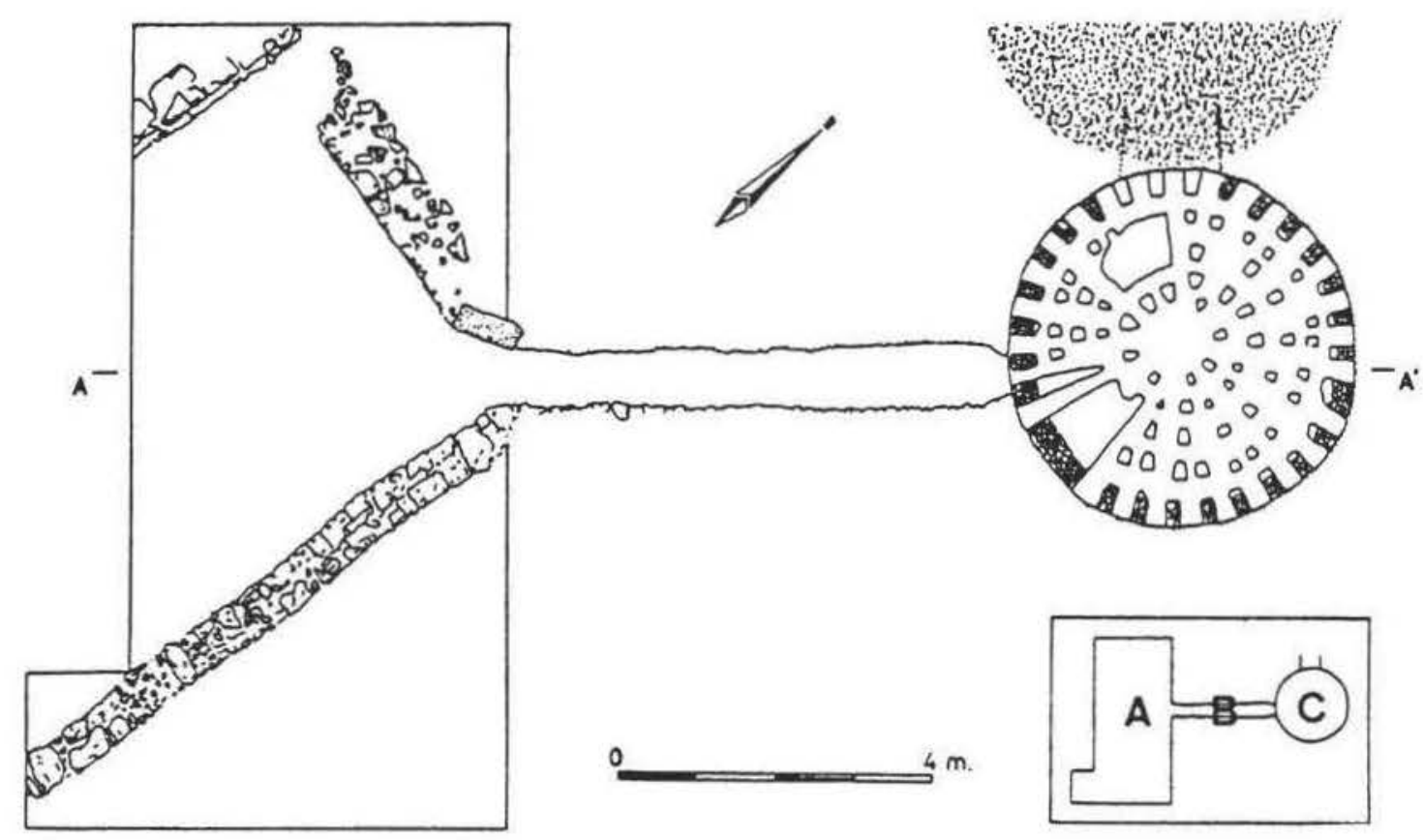

Figura 1. Planta del monumento donde pueden reconocerse el watrion (sector A), el pasillo (sector B) y el horno (sector C). El semicirculo de puntos sitúa el hoyo anexo al horno. El eje A-A' (señalado sólo en sus extremos) marca el trazado de la sección presentada en la figura 2.

vas (no podia ser de otro modo habida cuenta de la historia del enclave y las instrucciones de excavación: véase la nota 2), evidenciada por restos de plásticos, de cigarrillos, de botellas de vidrio, etc., siempre minoritarios con respecto a los abundantisimos fragmentos anfóricos. Estos no han sido íntegramente recogidos ni estudiados debido a su bajisima capacidad de información posicional y secuencial. Únicamente hemos recopilado, a modo de muestreo, la totalidad de los fragmentos de dos UU.EE. ${ }^{3}$, amén de aquellas evidencias que aportaran alguna nove-

\footnotetext{
'La práctica totalidad del material de época romana hallado durante la excavación es ceramico. Las unidades estratigráficas seleccionadas para el muestreo fueron las UU.EE. $2 \mathrm{~A}$ y $21 \mathrm{~A}$, las más ricas en material. Hemos renunciado a exponer el análisis comparativo entre ambos conjuntos porque su descontextualización impide valorar debidamente sus diferencias; no obstante, se constata que ta UE $2 \mathrm{~A}$, pese a contar con menor número de piezas. muestra mayor variedad que la UE $21 \mathrm{~A}$.
}

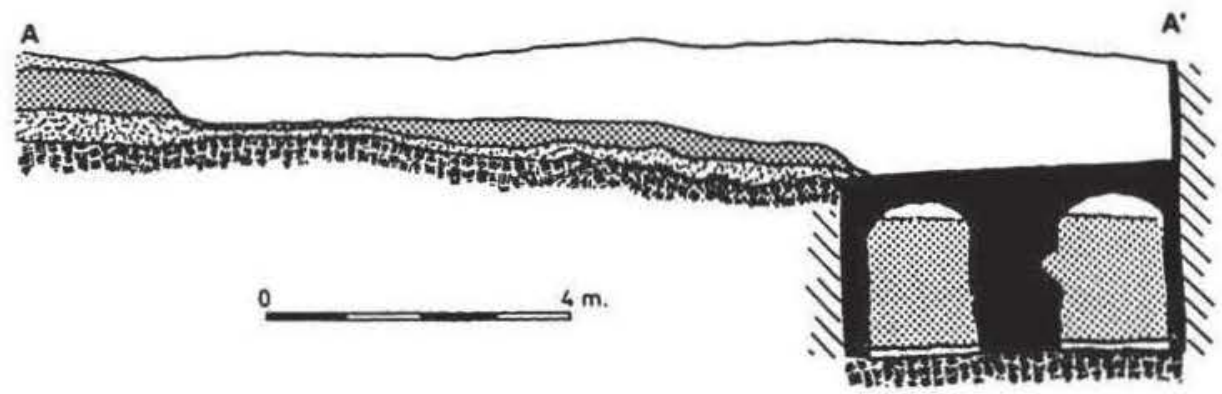

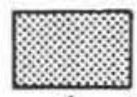

1

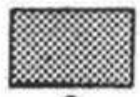

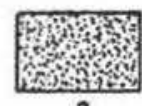

3

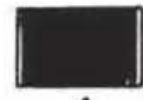

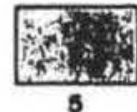

5

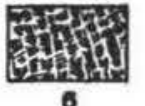

6

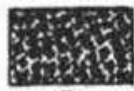

7

Figura 2.-Sección general del conjunto según el eje A-A' de la figura 1 . Los motivos gráficos núms. 1, 2 y 3 representan distintas UU.EE. sedimentarias de formación reciente; el núm. 4 señala la zona construida (paredes del horno, columna y parrilla); el núm. 5 señala la única UE. sedimentaria formada en época romana; los núms. 6 y 7 representan los niveles de base, estériles; el rayado señala las zonas de composición desconocida. 
dad al citado lote. Pese al nulo interés de su contexto. creemos que es posible obtener cierta información de dicho repertorio considerándolo como una muestra de algún momento de actividad del enclave.

\section{LAS EVIDENCIAS MATERIALES}

A continuación presentamos una somera caracterización del conjunto de las piezas, agrupadas de este modo: 1, pastas de ánforas; 2 , bordes de ánforas; 3 , pivotes de ánforas; 4 , signacula; 5 , fragmentos anfóricos que no determinan forma; 6 , terra sigillata italica y 7 , materiales de construcción ${ }^{4}$.

\section{Las pastas de ánforas}

Hemos diferenciado dos tipos de pasta atendiendo a la composición y textura de los fragmentos, clasificados mediante simple inspección visual. El primero de los tipos presenta, como rasgos generales, unas arcillas bien decantadas, con pocos desgrasantes, en general pequeños $(<0,5 \mathrm{~mm})$, de cuarcita blanca y de una sustancia negra que no hemos identificado - quizảs se trate de pequeñas motas de pasta de cerámica quemada-; además y ocasionalmente, contiene algunos fragmentos cerámicos de color rojo oscuro, de 3 a $7 \mathrm{~mm}$ de calibre. El color de la pasta puede variar del amarillento con matices verdosos hasta los tonos rosados, menos frecuentes, si bien ambos pueden adquirir matices rojizos o negruzcos, especialmente en las zonas de cocción defectuosa. Estas percepciones nos recuerdan la descripción de la arcilla típica de la forma 53 de Vegas s y algunas de las ánforas halladas en Conimbriga ${ }^{6}$; en ambos casos se trata de envases para salazones, el primero de ellos fechado desde época tardo-republicana hasta el siglo in d.C. y el segundo desde el año 25 a.C. y a lo largo de todo el siglo d.C., con especial concentración en época claudia.

Respecto al tipo 2, es una pasta rica en desgrasante arenoso, visible por igual en ambas superficies y en la fractura, de tonalidades marrones, a veces con matices grisáceos y violáceos. Suele presentar

\footnotetext{
- Existe un inventario detallado de todas las piezas recuperadas en el informe final de la excavación, depositado en la Delegación Provincial de Cádiz de la Consejeria de Cultura y Medio Ambiente de la Junta de Andalucía.

" «De color ocre-amarillento muy claro, presentando a menudo un matiz verdoson (Vegas, 1973, 132-133).

- "Fina, beige,... con engobe amarillo ligeramente verdoso..." (Alarçao y otros, 1976, 85).
}

engobe. de tonos más blanquecinos que la pasta. Tanto la tipologia de los fragmentos con ella elaborados como las descripciones de los distintos autores nos sitúan inequivocamente en la linea de las pastas tipicas de las Dressel 20 (Martin-Kilcher, 1987. Farbiabeln. A y B).

\section{Los hordes}

Se han distinguido cinco tipos de bordes en función de su morfología, los cuatro primeros elaborados con pasta del primer tipo y el quinto con pasta del segundo tipo?. El borde de tipo 1 es suavemente exvasado, con el labio completamente vuelto y pegado a la pared externa (fig. $3: 1$ ). El de tipo 2 es un borde exvasado con el labio engrosado en su remate y más o menos apuntado (fig. 3: 2 a 5). El borde de tipo 3 es nuevamente un borde exvasado, culminado en un labio de desarrollo vertical, cóncavo y corto, cuyo extremo inferior se une a la pared externa, formando el conjunto un cuerpo de tendencia triangular (fig. 3:6). El de tipo 4 es similar al anterior pero con algunas diferencias: la zona superior del labio queda normalmente marcada por un baquetón, la distancia de éste al inferior es casi el doble que en el tipo anterior, y su separación del cuello es más marcada (fig. 3:7). Por último, el borde de tipo 5 es un borde de Dressel 20 que sobre un corto cuello cilindrico levanta un labio de tendencia globular, cóncavo al interior y convexo al exterior (fig. 3:8).

Contamos con 45 bordes de tipo 1, que resultan similares a un ejemplar hallado en Conímbriga, sobre una forma Haltern 70 , procedente de contextos fechados de Augusto a Trajano y elaborada con una pasta «...de color naranja grisáceo...de textura arenosa", que recuerda a nuestro segundo tipo de pasta (Alarçao y otros, 1976, 83 y pl. XX:11). En la misma linea se sitúan dos de los hallados en el depósito de la Rue de la Favorite, en Lyon, también sobre formas Haltern 70 , con pasta de «color gris rosado...similar a las de las ánforas Dressel 20 m (Becker y otros, 1977, 76 y fig. 11: 1 y 3). Y también al mismo modelo responden algunos de los bordes hallados en Oberaden (tipo 82 del yacimiento) y en Rödgen, «enclave fechado en los primeros años de la era», sobre un ánfora que no dudamos en clasificar como Haltern 70 (Beltrán, 1970, 390 y 392; fig. 152:10 y 12; fig. 153:10). Estos modelos

\footnotetext{
7 Para la caracterización e inventario de estos fragmentos se han considerado, además del tipo, el diámetro, y la pasta. En los casos de pivotes $y$ asas se han considerado otros atributos similares pero adaptados a cada elemento.
} 

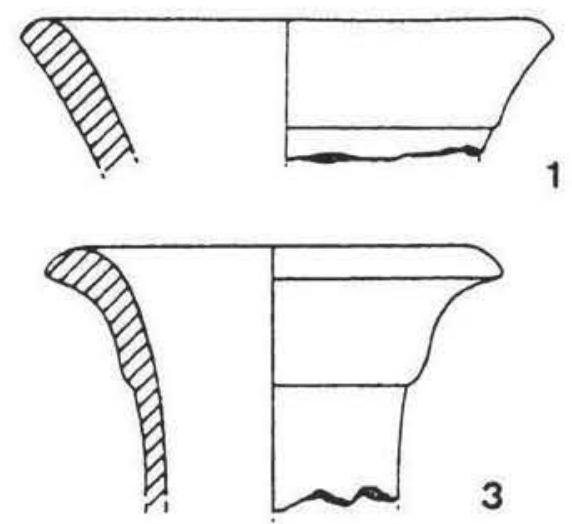

3

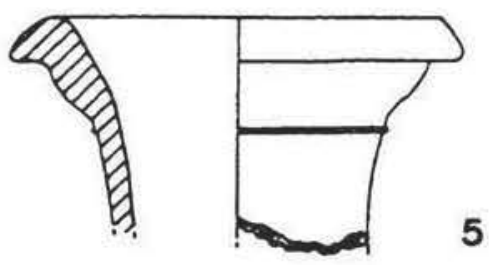

5
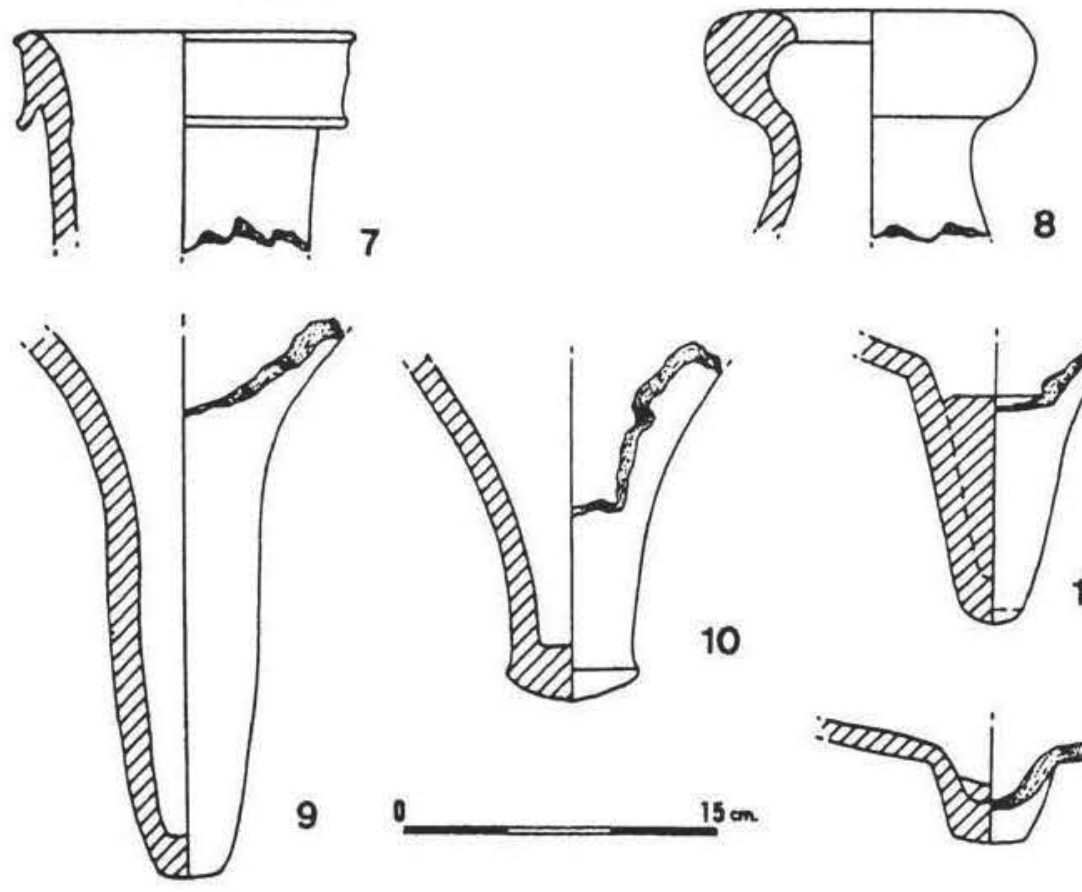

10
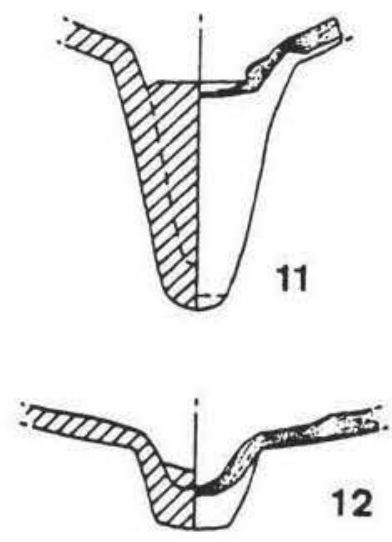

Figura 3.-Tipologia de bordes y pivotes de ánforas: 1, borde de tipo $1 ; 2$ a 5 , variantes de bordes de tipo 2; 6, borde de tipo 3 ; 7 , borde de tipo $4 ; 8$, borde de tipo $5 ; 9$ y 10 , pivotes de tipo 1 convexo y cóncavo respectivamente; 11 , pivote de tipo 2 ; 12 , pivote de tipo 3 . 
han sido agrupados por Peacock y Williams en su tipo $15^{x}$.

Nuestro tipo 2 de borde es el más representado 435 fragmentos - y muestra una gran variabilidad formal, circunstancia ya documentada, por ejemplo, en el depósito del Ebro, en Zaragoza, y que incluso sirvió en su dia a Pelichet para proponer una secuencia cronológica, por el momento no confirmada (Beltrán, 1970, 296). Podemos encontrar sus distintas variantes en ambientes y épocas afines a las de los anteriores. Por ejemplo, en fragmentos de bordes procedentes de Rödgen (Beltrán, 1970, fig. 153:9), o de los depósitos de Paso a Nivel y de Villanueva, en Puerto Real (Cádiz), en este último lugar también sobre formas completas Peacock y Willimas 17 , fechadas en época de Claudio merced a una moneda cuyo contexto preciso es desconocido (Jiménez, 1971, 141. Peacock, 1974, 236, fig. 3: 3, 4 y 14, fig. 4: 1-3. Beltrán, 1970, fig. 160: 55 a 57). En el pecio corso de Lavezzi, de época claudio-neroniana, lo constatamos en un ánfora del tipo Dressel 8 (Tchernia, 1969, 495 y fig. 50). Sobre formas Peacock y Williams 19 completas se encuentran en Augst, en Jerez de la Frontera, nuevamente en el depósito de Villanueva, o en Cúllar Vega, Granada (Beltrán, 1970, figs. 154:13, 174:10 y 175:15 y 17). También los encontramos en el depósito augusteo de la Rue de la Favorite, en Lyon, igualmente sobre ánforas de tipos Peacock y Williams 17 y 19 (Becker y otros, 1977, figs. 14 y 15).

En resumen, el tipo no presenta grandes diferencias cronológicas ni de distribución con respecto al anterior y, en términos generales, aparece sobre for-

\footnotetext{
* También hallamos coincidencias formales en otros recipientes, aunque no $\tan$ ajustadas a nuestro modelo como en el caso anterior, pues, pese a tratarse igualmente de labios completamente plegados, muestran mayor sección, si bien si coinciden en el tipo de pasta con los nuestros. Nos referimos, por ejemplo. a una forma procedente de Haltern que Beltrán identifica con un tipo 70 del yacimiento epónimo (Beltrán I), pero cuyo aspecto piriforme y largo pivote hueco nos recuerdan más a los modelos Dressel 7. Pensamos también en un fragmento de borde con asas hallado en el pecio de Percheles, en Almeria (respectivamente Beltrán, 1970, fig. 154:16; fig. 157:41 y pàg. 397). Es asimismo el caso de un ejemplar hallado en el estrecho de Bonifacio, en Sicilia, identificado por Vegas como tipo Oberaden 81 y asimilado, por tanto, a su forma 53 (Vegas, 1963, fig. 48:1); o también el de uno de los ejemplares documentados en el horno de "El Rinconcillo", en Algeciras, de tipo Dressel 7. Sus fechas respectivas coinciden con las anteriores y las prolongan ligeramente (Sotomayor, 1969, 398 y fig. 4; y Beltrán, 1970, 390 y sigs.). La morfologia de los ejemplares mencionados en último término nos remite a un tipo $16 \mathrm{~A}$ de Peacock y Williams (Dressel 7-11, Beltrán I), denominación que agrupa formas relativamente variadas, elaboradas en distintos lugares, desde la zona que nos ocupa hasta Cataluña, y extendidas prácticamente por las mismas áreas y en las mismas fechas que la anterior.
}

mas Peacock y Williams 17 (Beltrán I, Camulodunum 186A), Peacock y Williams 18 (Beltrán IIA, Dressel 38, Camulodunum 186C. Pelichet 46, Callender 6) o Peacock y Williams 19 (Beltrán IIB).

Los tipos 3 y 4 guardan cierto parecido y su presencia resulta casi testimonial: ocho y dieciocho fragmentos respectivamente. Su dispersión y cronologia ofrecen un panorama muy similar a los anteriores, pues si bien las variantes de tipo 3 suelen ser más frecuentes en formas Dressel IA, las hallamos también sobre formas Oberaden 80 y 82 del yacimiento epónimo, y en el depósito del Ebro (Beltrán, 1970, fig. 152: 1, y 2 a 4), en ambos casos en niveles augusteos. El tipo 4 está mejor representado. Lo encontramos en Gabii, en un fragmento de borde sin posible adscripción tipológica (Beltrán, 1970, fig. 153: 5), en el depósito del Ebro, en Zaragoza, sobre forma Peacock y Williams 16 ó 17, fechada en torno al 45 d.C. (Beltrán, 1970, 392, fig. 155: 20). También lo vemos en Pollentia, en dos fragmentos de borde de tipo no reconocible, fechados en torno a la segunda mitad del siglo I d.C. e incluidos por la autora en su tipo 53 (Vegas, 1973, fig. $48: 4$ y 5 y 133).

Además, el borde de tipo 4 también aparece en ánforas distintas a las que venimos considerando; quizás uno de los ejemplos más explícitos sea el que Joncheray agrupa bajo su epígrafe: «Ánforas romanas clásicas, con labios rectos o poco inclinados» ${ }^{9}$. Su cronología, siempre según el mismo autor, es tardía dentro de la general del grupo, que oscila entre 40/45 d.C. y finales del siglo II d.C. (Joncheray, 1976: 19, pl. IV).

El tipo 5, cuatro fragmentos, corresponde claramente a ánforas olearias Dressel 20. Su perfil permite algunas precisiones, pues coincide con algunos de los hallados en Augst en fechas próximas a mediados de la primera centuria (Martin-Kilcher, 1987, Beilage 1: 18, 19, 23, 47).

\section{Los pivotes}

Hemos diferenciado tres tipos en función de su morfología. El pivote de tipo 1 es un suave tronco de cono muy alargado y hueco, y muestra dos variantes, una con las paredes convexas (fig. 3: 9) y otra con las paredes cóncavas (fig. 3:10); el pivote

\footnotetext{
${ }^{9} \mathrm{El}$ autor propone un origen español para este tipo, y concretamente para el ejemplar $n^{\circ} 45$ de la figura antes citada, cuyo borde resulta muy parecido a los nuestros. El ejemplar que comentamos fue hallado en Saint Raphaël (Var), donde también se documentan ánforas análogas a las que hemos comentado anteriormente (Joncheray, 1976: 19, planche IV).
} 
de tipo 2 es un tronco de cono macizo (fig. 3:11) y el de tipo 3 (fig. 3:12) es un tapón troncocónico, corto y semimacizo.

Los pivotes ofrecen una información más limitada. En general, cabe admitir que los de tipo 1 constituyen un remate frecuente en las formas Peacock y Williams 17 y 18 . El tipo 2, siempre elaborado con el segundo tipo de pasta, es un remate caracteristico de Haltern 70 (Peacock y Williams 15), ảnfora, recordemos, no constatada entre los fragmentos de borde, por más que si hayamos observado su influencia en los bordes - tipo 1-de algunas ánforas de salazón elaboradas con la pasta tipica del horno. El tipo 3 se presenta siempre elaborado con pasta de tipo 2 y corresponde claramente a un fondo de ánfora Dressel 20.

\section{Los "signacula"}

Se trata de un lote de 17 fragmentos que conservan total o parcialmente un signaculum impreso antes de la cocción, siempre de forma circular o paracircular, estampado en positivo sobre ánforas elaboradas con pasta del tipo 1. La relación de epigrafes documentados es la sigiente: $A Q A, M . A . A[.] \overline{A T}$., $D[] A .. A . \overline{A T}^{10}, \overline{A L}($ ?), y palmeta única dispuesta en horizontal.

Los epigrafes del grupo $A Q A$ muestran siempre la letra central ligeramente por debajo de las otras y las tres quedan enmarcadas arriba y abajo por palmetas - 0 acaso espigas (?) fig. 4:1 a 10).

Los epigrafes de los grupos M.A.A[.] AT. (fig. 4: 11 y 13 ) y $D[]. A \cdot A . \overline{A T}$. (fig. $4: 12$ ) exhiben una indudable unidad morfológica, plasmada en una idéntica disposición de las letras, pese al cambio en las consonantes libres. Los motivos se disponen conforme a un esquema radial cruciforme ligeramente descentrado - pues sus ejes no se alinean exactamente sobre los diámetros del círculo-que entraña problemas respecto al orden de la lectura.

Contamos con dos epigrafes representados una sola vez: un probable nexo $\overline{A L}$ flanqueado por sendas palmetas paralelas a sus astas (fig. 4:16), y una gran palmeta que ocupa casi todo el espacio de la pequeña impronta circular (fig. 4:17). Este signaculum aparece junto a otro, del tipo de letras opuestas

\footnotetext{
${ }^{10}$ En ningún fragmento se han documentado integramente los cuatro signos de interpunción - siempre triangulares- -que reseñamos en el texto; los transcritos corresponden a lo observado en el conjunto de las piezas. La lectura del nexo $\overline{A T}$ no es absolutamente segura, puesto que no contamos con ningún signo completamente legible.
}

por sus bases (fig. 4:12), en el único fragmento del lote doblemente sellado.

Aunque el estado de conservación de estos signacula no permite determinar con toda precisión cuántos cuños están representados, es evidente que dentro del grupo AQA hay al menos tres grupos: el de los sellos con palmetas en el mismo sentido (fig. 4:5 y 6), el de aquéllos donde el trazo de la $Q$ no divide en dos grupos las hojas superiores de la palmeta inferior (fig. 4:7), y finalmente, aquéllos donde si lo hace (fig. 4:1 a 4), sin seguridad de que todas estas improntas procedan del mismo sello.

Los signacula fueron aplicados sobre el cuerpo del ánfora, y en el único fragmento morfológicamente identificable aparece junto a la base de una de las asas, precisamente donde suelen figurar en los escasos ejemplares hallados (Joncheray, 1976, 43). La observación de la dirección de las lineas del torno de la cara interna de cada fragmento con respecto al eje de lectura del sello nos permite concluir que no existe norma alguna en la orientación de la impronta. Los encontramos dispuestos en paralelo a ellas, pero también formando los más diversos ángulos. En todas las letras nos hallamos ante caracteres trazados con cierto esmero y, además, acordes con los cánones de la mejor tradición epigráfica. Ello es perceptible, por ejemplo, en la posición recta y bastante centrada del asta transversal de la A, o en las astas ligeramente divergentes de la $\mathrm{M}, \mathrm{o}$ en la larga virgula de la $Q$.

Su lectura es muy problemática debido a lo escueto del texto. Cabe suponer que nos hallamos ante tria nomina. Cuando las iniciales son más de tres, por ejemplo en el caso del grupo de letras opuestas por sus bases, Benoit propone que quizás se le haya añadido el nombre de un villicus o un esclavo (Benoit, 1957, 279), o tal vez el del alfarero, según la interpretación de Remesal, quien sugiere que en el caso del aceite bético, los nombres impresos en los sellos podrían corresponder a miembros de las oligarquías locales (Remesal, 1989, 490 y 493). La lectura e interpretación del signaculum del nexo AL $\mathrm{y}$ del de la palmeta única resultan aún más dificiles ".

No llama menos la atención su rareza, y ya Beltrán apuntaba la escasa frecuencia de marcas sobre las ánforas de salazón. No obstante, tenemos constancia de la aparición de signacula del tipo AQA en Camulodunum, sobre un ánfora del tipo $186 \mathrm{~A}$ (Ca-

\footnotetext{
"Un esquema compositivo similar, una única letra rodeada de un círculo, se ha documentado en un horno próximo geográfica y tipológicamente al nuestro: Rancho Perea (Chic, Giles y Sáez, 1980, 48).
} 

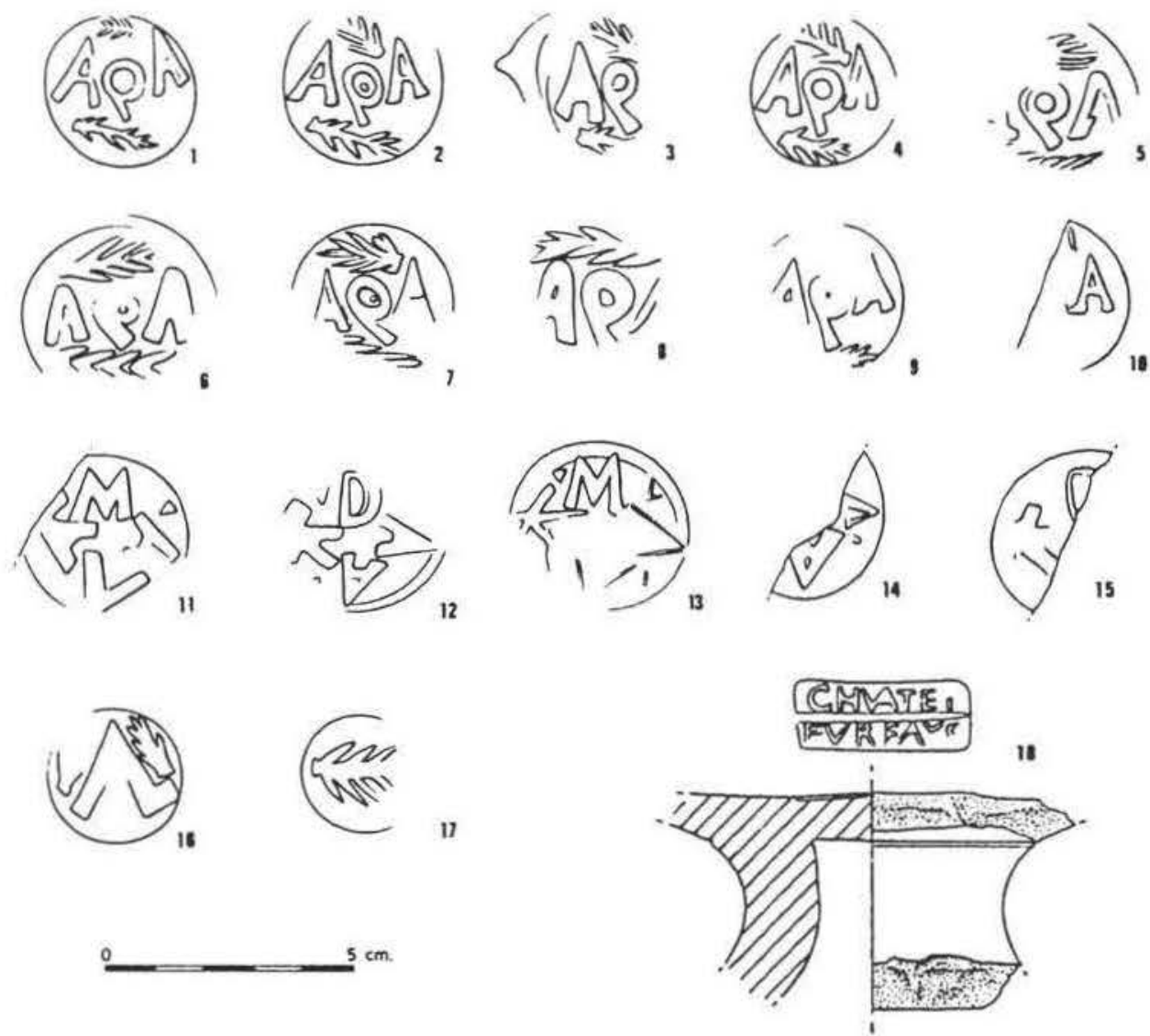

Figura 4.-Signacula. Se presentan todos los hallados en la excavación. 1, 2, 3 y 4, ejemplares del tipo AQA con las hojas de la palmeta inferior separadas por el trazo inferior de la Q. 7 único ejemplar de tipo AQA con las hojas de la palmeta inferior no separadas por el trazo inferior de la Q. 5 y 6. dos sellos del tipo AQA con las palmetas en el mismo sentido.8,9 y 10, piezas del tipo AQA sin diferenciar; $11,12,13,14$ y 15 , tipo de letras opuestas por sus bases; 16 , tipo "A» con palmetas. 17, tipo de palmeta única. 18, fragmento de TSI con sello.

llender, 1965, 72; fig. 3:43), y también en Fôret de Compiègne. Ahora podemos confirmar su origen portorrealeño, ya intuido por Beltrán $(1970,109$, nota 163$, y 417$)$.

\section{Fragmentos que no determinan forma}

Los fragmentos anfóricos que no determinan forma y no tienen marcas han sido también recogidos en el muestreo, clasificados por pastas y pesados. Han arrojado los siguientes resultados: primer tipo de pasta, 2.496,5 kg (96,3\%); segundo tipo de pasta, $94 \mathrm{~kg}(3,6 \%)$.

Este dato cobra cierto relieve si observamos que con el primero de los tipos se fabricaron la mayoria de los fragmentos hallados en la excavación, mientras el segundo está asociado a bordes y pivotes de Dressel 20 y a pivotes de Haltern 70. Resulta, por tanto, lícito hablar de un conjunto propio del horno
- el mayoritario - y de otro ajeno; si bien la falta de contexto impide profundizar en la relación entre ambos, sin duda interesante. Por otro lado, el total de fragmentos con signaculum pesa $4 \mathrm{~kg}$; es decir, que apenas el $0,1 \%$ de toda la arcilla era marcada ${ }^{12}$ : una cantidad muy escasa y alejada de cualquier proporción identificable entre el número de ánforas selladas y lisas.

No queremos concluir los comentarios sobre el conjunto anfórico sin algunas consideraciones de carácter general. Así, por ejemplo, llama la atención la diferenciación formal de los envases de salazones que, no obstante, conservan ciertos rasgos comunes (perfil ovalado, largos y anchos cuellos, asas y pivotes largos). En principio, resulta extraña

${ }^{12}$ Los fragmentos con signaculum muestran una gama de tamaños similar al resto $y$, por tanto, puede resultar válida la comparación de sus pesos. 
tal hetereogeneidad para envasar un mismo producto, máxime si comprobamos la relativa homogeneidad de otros contenedores.

Como ya constató Zevi $(1966,231)$, todos los modelos son coetáneos. No podemos, pues, explicar la variabilidad como resultado de la evolución y por lo mismo también hemos de descartar la teoria - bastante atractiva - de una búsqueda de mejor relación peso/capacidad. ¿Cuál es, pues, la razón de estas diferencias? Admitiendo que la hubo, tan sólo nos sentimos capaces de sugerir alguna hipótesis. Por ejemplo, que tal variedad pudiera responder a una especialización formal en distintos derivados de la pesca: pescado en conserva, garum, liquamen, muria, flos, etc. En este sentido, seria interesante comprobar si existe alguna asociación entre las diversas formas y los tituli picti en los lugares de consumo, aunque tal empresa no parece fácil (Zevi, 1966, 232 , nota 70 ). Tampoco conviene descartar a priori otra posibilidad: que existiera alguna relación entre formas y sellos; si bien, dada la escasez de estos últimos, probablemente sólo pudiera ser contrastada en depósitos como los del Ebro, en Zaragoza, o Villanueva (Jiménez, 1971, 140-143) y Rota (López y Pérez, 1979), en Cádiz.

El lote considerado permite, por último, afirmar que estas ánforas fueron fabricadas por partes (pivotes, asas, cuellos y panzas). Este aserto, nada novedoso, se basa en la observación de varios fragmentos defectuosos, con fisuras en las zonas de ensamblaje.

El conjunto de fragmentos anfóricos delata, en resumen, la coexistencia de formas anfóricas Peacock y Williams 15 a 18 y Dressel 20 , unas elaboradas en el horno e importadas las otras. Por otro lado, sugiere un horizonte cronológico comprendido entre el cambio de era y los primeros decenios del siglo II d.C., si bien buena parte de las referencias coinciden en una franja situada aproximadamente en el segundo tercio del siglo I d.C.

\section{Terra sigillata italica}

Hemos hallado algunos fragmentos de TSI en el entorno del monumento; no superan la media docena ${ }^{13} \mathrm{y}$ todos son minúsculos e inexpresivos excepto

\footnotetext{
13 No obstante, parece que tan menguado repertorio no da fe de su representación original, constituye simplemente lo respetado por algunos aficionados locales que disponen, al parecer, de una nutrida colección.
}

uno: un fondo de cáliz y extremo superior del fuste de una copa de pasta muy tamizada y engobe bien conservado, una forma genérica Drag. 11, muy posiblemente decorada con relieves.

El fondo interno de dicha copa muestra un sello completo, con cartela rectangular dividida en dos registros superpuestos. En el superior, es claramente legible el texto $C N \overline{V A} T E I$; en el inferior, la grafia es menos nítida, aunque creemos probable la lectura EVRIALVS, con $V$ reducida a la mitad superior del registro. Longitud de la cartela: $22 \mathrm{~mm}$; anchura total: $9 \mathrm{~mm}$ (fig. 5:18).

El conjunto de la producción firmada por Ateius constituye uno de los más extensos e interesantes dentro de la TSI, y como tal ha sido objeto de intenso debate. Su presencia en la península ibérica no es infrecuente, pues ha sido hallado en casi todos los enclaves de cierta relevancia de la Hispania romana (Beltrán, 1990, 68); por ejemplo, en Itálica (López Rodriguez, 1979, 44), o en Numancia (Romero, 1985,31 y 35 ), en torno a los primeros decenios del siglo I d.C. No obstante, su asociación al nombre de Eurialus resulta menos habitual, aunque no desconocida. En Hispania, ha aparecido en Tarragona, Granada (Oxé-Comfort, 1968, 70, 164, 2 y 4) y Mérida (Beltrán, 1990, 68). En el occidente romano, se ha constatado su presencia en lugares tan lejanos como Saturnia, Autun, Paris, Vindonisa, Maguncia o Silchester (Oxé-Comfort, 1968 , 70) y, sobre la «forma genérica Drag. 11, cáliz con copa o pedestal», en Numancia (Romero, 1985, 22, fig. 1:4 y 5 ).

Ciertamente, un rasgo peculiar de nuestro fragmento es el nexo, por lo demás bien clásico, $\overline{A V}$. no aparece en ninguna de las piezas asociadas con el nombre de Eurialus e incluso en ninguna de las firmadas por el propio Ateius en solitario o combinado; al menos, no tan claramente como en el caso que nos ocupa. Quizás, y vista la indudable existencia del nexo en nuestro fragmento, hubiera que interpretar en el mismo sentido la desviación del asta vertical derecha de algunas de las $\mathrm{N}$ del praenomen de otros sellos (p. ej., Oxé-Comfort, 1968, 57: 28, 59: 117 , o especialmente, $60: 9.72$.b). La forma de la cartela es común en este ceramista y su disposición sobre el fondo interno de la copa obedece a los usos más frecuentes en este contexto.

La complejidad de esta producción no permite aún determinar si nos hallamos ante un producto elaborado en Arezzo o ante uno procedente de cualquiera de sus filiales galas (Beltrán, 1990, 66). Su cronologia ha de entenderse comprendida entre finales del siglo I a.C. y los primeros decenios de la siguiente centuria. 


\section{Materiales de construcioion}

En general, no han sido inventariados individualmente sino por lotes, y únicamente recogidos en las UU.EE. tomadas como muestra. Entre ellos contamos con tégulas, imbrices, adobes, piedras y fragmentos de tuberia, elementos habituales y de los que poco podemos obtener, razón por la que han sido omitidos en el presente texto. Nos referiremos, pues, únicamente a los materiales que vayan a ser mencionados en las consideraciones finales.

Entre ellos contamos con varios fragmentos similares de basas de barro cocido. Uno de los tipos presenta un plinto que soporta un cuarto bocel sobre el que apoya otro, de sección menor y ultrasemicircular, culminado por un listel que levanta apenas medio centímetro. El otro es más sencillo: un cuarto bocel que soporta dos listeles escalonados. El diámetro de la base se sitúa en ambos casos en torno a los $50 \mathrm{~cm}$ y su altura máxima en torno a los $6-8 \mathrm{~cm}$.

Ladrillos y/o baldosas. Abundantes ambos. Los ladrillos, macizos, tienen una sección media en torno a $\operatorname{los} 5 \mathrm{~cm}$. Sus formas son tanto semicirculares como rectangulares, o quizás trapezoidales. No se conserva ninguno completo. Las que denominamos baldosas tienen, por término medio, una sección de $2,3 \mathrm{~cm}$ y sólo contamos con un ejemplar completo, de forma romboidal, cuyos ejes mayor y menor miden respectivamente 14 y $8 \mathrm{~cm}$.

Fragmentos de revoque o revestimiento. Hallados en ambas UU.EE. de muestra. Uno de ellos es un fragmento bastante grueso $(4,5 \mathrm{~cm}$ en su sección máxima) formado por cal y arena, con varias capas externas de enlucido blanco, basto, sin evidencias de decoración. El otro formó probablemente parte de un elemento constructivo-ornamental, pues es un cuerpo de arcilla de unos $15 \mathrm{~cm}$ de longitud máxima que conserva dos superficies curvas en lados opuestos, recubiertas ambas por un enlucido amariIlo al exterior.

Una de las UU.EE. definidas en el atrio resultó ser un amontonamiento de gruesas teselas calcáreas, blanquecinas, de algo más de $15 \mathrm{~mm}$ de lado, aún con restos de la argamasa que las unía y mezcladas con fragmentos de adobe, todo ello producto de un vertido no muy antiguo.

También en el «atrio», apareció un fragmento de placa de mármol de color rojo con vetas blancas, pulido por ambas caras, con una sección algo inferior al centímetro y de forma irregular, por fractura; mide aproximadamente $5 \mathrm{~cm}$ de anchura por $6-8 \mathrm{~cm}$ de longitud.

\section{CONSIDERACIONES GENERALES}

En principio, cabria pensar que nos hallamos ante un establecimiento similar a aquellos que abastecieron de ánforas a los circuitos comerciales vinicola y oleicola. Esto es, ante una explotación agraria, una villa. que dedica parte de sus recursos a la producción de ánforas. Ahora bien, existen dos obstáculos para la aceptación inmediata de esta idea.

En primer lugar, nuestro horno se sitúa en una zona rica en restos de ánforas y elementos afines, en su mayoria relacionados con las salazones y tradicionalmente interpretados como la evidencia de un sistema industrial peculiar. Ya Callender sugirió que la gran concentración de restos anfóricos - hornos, depósitos y testares de envases de salazones - en torno a Cádiz evidenciaba la existencia de talleres profesionales y tal hipótesis ha gozado de aceptación generalizada desde su formulación. Beltrán llegó incluso a señalar el término de Puerto Real como uno de los puntos donde tendria lugar una fabricación conforme a este sistema (Beltrán, 1970, 109 y nota 163) y Peacock y Williams, apoyándose nuevamente en la superabundancia de restos, matizaron que se trataría de una producción anfórica de artesanos independientes no vinculados a establecimientos rurales (Peacock y Williams, 1986, 37 y 41 a 43). Si bien posteriormente, Beltrán apuntó que existiria una dependencia directa de los centros de producción de derivados del pescado (Beltrán, 1990, 18).

Es evidente que nuestro enclave está en esa zona tan especial; no obstante, ¿responde a ese esquema? Se trata, sin duda, de un alfar en toda regla, pero ¿es sólo uno de estos talleres profesionales? Algunos de los elementos descubiertos sugieren ciertas dudas al respecto. Nos referimos, por ejemplo, al cáliz Drag. 11, o al fragmento de placa marmórea - quizás parte de un zócalo o de un pavimento de opus sectile - También pensamos en el montón de gruesas teselas hallado en el atrio, sin duda restos de un pavimento de cierto empaque $\mathrm{y}$, asimismo, en los fragmentos de revoque con enlucido de color. Otro tanto cabe afirmar de las basas de columna y ladrillos semicirculares que, por su escasez - no más de una docena- más parecen elementos de uso que productos venales. Aunque escasas, tales evidencias vienen a arropar el escueto comentario de Jiménez respecto a ciertas estructuras, interpretadas como restos de vivienda (Jiménez, 1971, 148) y nos permiten sospechar que no estamos ante un mero alfar, sino ante una residencia que contó 
con hornos entre sus instalaciones ${ }^{14}$, si bien no podemos discernir si se trata de una explotación agricola, como parece lógico, o un hábitat de otro tipo.

Como cabe observar, el principal argumento para resaltar la singularidad de la produción anfórica de la zona es el de su elevado número de restos. Pero quizás tal concentración pueda ser entendida como un fenómeno similar al detectable entre los rios Genil y Guadalquivir (Remesal, 1989, 490 y fig. 1), relacionado con la producción del aceite bético, o entre los rios Besós y Arenys, en el caso del vino layetano (Prevosti y Clariana, 1987, 202). Es decir, creemos estar ante una repetición del fenómeno de concentración de alfares en una comarca especializada en la producción y exportación de un bien de consumo alimenticio.

Por lo demás, su emplazamiento resulta acorde con las pautas más normales: unas buenas condiciones naturales de comunicación (ibidem, 204-205) merced a su instalación en un paisaje de marismas sin duda mucho más próximo a alguna via de agua de lo que lo está ahora. (Corzo, 1980, 12 y sigs., fig. 2; también Lagóstena, 1993, pág. 103 y fig. 4) y unida a otros lugares de actividad alfarera: el caserio de Jarana, Torre Alta y el pago de Casines, por «una especie de carril formado de barro y trozos de ánforas») (Jiménez, 1971, 142) ${ }^{15}$.

$\mathrm{Si}$, abundando en la idea anterior, nos detenemos un poco en la consideración de las posibles similitudes entre las industrias del vino y aceite $\mathrm{y}$ de las salazones, podemos observar una afinidad básica determinante: en todos los casos se trata de comercializar productos de estación, pues del mismo modo que la producción de aceite y vino dependen del ritmo de las cosechas, la industria de la salazón se apoya especialmente en la pesca estacional del atún, a su paso por el Estrecho de Gibraltar para completar su ciclo reproductor en los meses de mayojunio y julio-agosto (Jiménez Contreras, 1986, 23 y 29). En los primeros casos, es precisamente ese carácter de producción estacional un argumento para explicar la elaboración de ánforas en las villae, con-

\footnotetext{
"Además del horno que nos ocupa, Jiménez (1971, 147) encontró "un hermano gemelo», y López (1981) dos hornos más; es decir, existen al menos 3 ó 4 hornos.

is Se trataria, además, de un enclave relativamente alejado de los nủcleos de población, norma reiterada constantemente a lo largo de la historia y atestiguada para esta época en la Ley de Urso (Blázquez, 1978, 443). A buen seguro, también se tuvo en cuenta para su emplazamiento el acceso a la materia prima, la arcilla, aún abundante en el término, como testimonia algún topónimo actual (Los Barreros), asi como el aprovisionamiento de combustible.
}

forme a un sistema económico de actividades yuxtapuestas y complementarias que permiten cierta autosuficiencia de cada hacienda. tal y como propugnan los tratados clásicos. ¿No podria haber ocurrido algo similar en el caso de la industria salazonera?

Por otro lado, este carácter de actividad estacional se ve reforzado en todos los casos por las condiciones de navegabilidad del Mediterráneo, via por la que llegaron nuestras exportaciones a los yacimientos italianos, ingleses y alemanes citados anteriormente. Como es bien sabido, este mar fue el principal cauce de comercio de la época, pero sólo era accesible en verano, resultaba inseguro desde septiembre a mayo y muy peligroso entre noviembre $y$ marzo (Peacock y Williams, 1986, 63), época en la que las travesias se reducian al minimo. Por tanto, no solo la producción, también la comercialización de estos productos está sometida a limitaciones y ritmos afines.

Pero las analogias no se limitan a estos aspectos estructurales, otro tanto ocurre con algunos procedimientos básicos, que denotan una organización similar: pensamos en los signacula. En nuestro caso contamos con diecisiete piezas, impresas probablemente por siete matrices, que estamparon cuatro marcas distintas. Tanto la presencia de estos elementos como su heterogeneidad resultan moneda corriente en los alfares vinicolas y oleícolas (Prevosti y Clariana, 1987, 205; Remesal, 1987, 42) y ha sido interpretada, según una hipótesis generalmente aceptada, como testimonio de la producción conjunta de varios alfareros -o mejor propietarios de alfares-, uno de ellos titular del horno y el resto otros productores locales.

Prevosti y Clariana $(1987,205)$ han sugerido que las ánforas selladas funcionarian como marcadores de lote, señalando los limites de los distintos conjuntos cuando hubiera posibilidades de mezcla, y esto ocurrirfa al agrupar los envases, ya rellenos, en depósitos, a la espera de su transporte.

Por nuestra parte, valorando la implantación de los signacula sobre el barro fresco, la coexistencia de lotes de propietarios diferentes y la importancia numérica de los fragmentos con defectos de cocción, pensamos que estas marcas podrian haber sido efectivamente marcadores de lote, pero utilizados, al menos por vez primera, durante la cochura, pues es la fase más delicada y dificil de controlar en todo el proceso de fabricación y donde caso de producirse desperfectos, que los hubo, sería importante saber exactamente a qué lote habian afectado. De acuerdo con este modelo, no tuvo porqué existir una proporción constante entre las ánforas impre- 
sas y las lisas, como realmente ocurre, pues ésta dependeria de la composición de los lotes de cada hornada.

Creemos, en definitiva, que existen varios aspectos comunes entre nuestro horno y aquéllos que fabricaron envases para el vino y aceite hispanos, asi como entre las propias actividades básicas implicadas, y que cabe, pues, que todo ello haya propiciado respuestas similares en cuanto a la organización general.

Sin embargo, subsiste un punto oscuro: el de la relación del horno y su posible villa, con la/s factoría/s de salazón. Como es sabido, las villae vinícolas y oleicolas dedican parte de sus fundi al cultivo de un producto característico de la zona, envasado y exportado en las ánforas elaboradas en la propia hacienda. Pero en nuestro caso, existe una clara disociación espacial entre el lugar de producción - las factorias de salazón costeras - y el de elaboración de los envases, sin que se haya comprobado por el momento la existencia de vínculos entre ambos lugares. Atendiendo a todo lo anterior, cabe plantear tres hipótesis respecto a esta relación. Pudiera ocurrir que este enclave fuera una residencia-taller de alfareros, bien independientes, bien dependientes de las factorias de salazón; o quizás se tratara de una explotación agraria tipo villa, que añade a sus actividades la elaboración de recipientes cerámicos, vendidos a los productores del contenido; o por último, es posible que los titulares de la hacienda mantuvieran intereses directos en la/s factoria/s de salazón, y viceversa. Decantarse decididamente por una de estas tres hipótesis exige encarar proyectos de investigación especificos para comprobar las implicaciones de cada enunciado, y en estas pesquisas puede jugar un importante papel la identificación de los nombres de las estampillas.

Estamos, en definitiva, ante un enclave surgido al calor de la actividad del "circuito del Estrecho»: una amplia región situada a ambos lados del Estrecho de Gibraltar y especializada en la elaboración de derivados del pescado (Ponsich, 1988, 57 y sigs. y figs. 6 y 17), cuyo origen se remonta, según las fuentes, a varias centurias antes de nuestra era, si bien actualmente no existen pruebas arqueológicas de su funcionamiento anteriores a la época de Augusto (Ponsich, 1988, 231 y Beltrán, 1970, 598). A partir de este momento, que coincide con el cambio de sentido del flujo comercial entre Italia y las provincias occidentales (Tchernia, 1989, 531), comienza un progresivo despegue del garum que «sembra penetrare rapidamente e senza ostacoli anche in regione che, almeno in un primo tempo, sembrano brestie ad accogliere l'olio spagnolo") (Zevi, 1966,
240, véase también Blázquez, 1978, 430). Su mayor difusión parece tener lugar durante el siglo primero de la era, continuando, con intensidad menor, durante la centuria siguiente (Vegas, 1973, 131 y 133). En general, se admite que este comercio no escapa a la decadencia generalizada del siglo III, aunque también se rastrea su perduración, modificando algunas de sus características, hasta época de los antoninos e incluso más allá (Beltrán, 1970, 109, 595 y 598: Ponsich, 1988, 234).

\section{REFERENCIAS BIBLIOGRÁFICAS}

Alarcao, J.; Delgado, M.; Mayet, F.; Moutinho, A., y PONTE, S. DA (1976): Fouilles de Conimbriga VI. Céramiques diverses et verres, París.

BÁdenas, P., y Olmos, R. (1988): «La nomenclatura de los vasos griegos en castellano. Propuestas de uso y normalización». Archivo Español de Arqueologia, 61, 61-79.

Becker, C.; Constantin, C.; Desbat, A.; Jacquin, L., y LAscoux, J. P. (1977): «Le dépôt d'amphores augustéen de la rue de la Favorite à Lyon». Figlina, 7, 65-89.

BELTRAN LLORIS, M. (1970): Las ánforas romanas en España. Monografias arqueológicas VIII, Institución Fernando el Católico, Zaragoza.

BELTRÁN Lloris, M. (1983): «Las ánforas romanas de salazones de forma I, variante b, de la Bética». Homenaje al Profesor Martín Almagro Basch, IV, 43-52.

Beltrán Lloris, M. (1990): Guía de la cerámica romana. Pórtico, Zaragoza.

BENOIT, F. (1957): «Typologie et epigraphie amphoriques. Les marques de Sestius». Rivista di Studi Liguri, anno XXIII, n. ${ }^{\circ}$ 3-4, 247-285.

BenoIT, F. (1960): «Nouvelles épaves en Provence». Gallia, XVIII, 41-56.

Blazquez, J. M. (1978): Economía de la Hispania Romana. Nájera, Madrid.

Callender, M. H. (1965): Roman Amphorae with Index of Stamps. Oxford University Press, Londres.

CAMpano Lorenzo, A. (en prensa): «Excavación arqueológica en el horno de ánforas de "El Olivar de los Valencianos", Puerto Real, Cádiz. Comentarios sobre la estructura». Anuario Arqueológico de Andalucia.

Corzo SÁnchez, R. (1980): «Paleotopografía de la bahía gaditana». Gades, 5, 5-14.

Chic, F.; GILES, F., y SÁEZ, A. (1980): «Horno cerámico romano del Rancho Perea (San Isidro del Guadalete)». Boletín del Museo de Cádiz, I (1978), 43-52. 
JiMth / Cisntros, M. J. (1971): Historia de Cädiz en la Antigüedad. Instituto de Estudios Gaditanos, Cádiz.

JiMI:NI, CONTRI:Ras, S. (1986): "La industria del pescado en la antigüedadn. Revista de Arqueologia. $68,20-34$.

Jonchit RAY, J. P. (1976): «Nouvelle classification des amphores découvertes lors des fouilles sous-marinesn. Cahiers d archeologie suhacuatique, Frejus.

Juan Tovar, L. C., y Birmuid/ Midel. A. (1989): "Hornos de época republicana en Cataluña". Revista de Arqueologia, 98, 40-47.

LAGiOSTENA BARRIOS, L.: "Alfar romano del cerro de Ceuta (Puerto Real, Cádiz)». Habis, 24, 95-104.

LOPF̌ DE LA ORDFN, M.“ D. (1981): «Hornos cerámicos romanos en el "Olivar de los Valencianos" (Puerto Real, Cádiz)". Boletin del Museo de Cädiz, II, 59-62, 1979-1980.

López de l.a Orden, M. a D., y Pérez Lóplz, I. (1980): «Depósito de ánforas en las cercanias de Rota». Boletin del Museo de Cádiz, I (1978), 51-54.

López Ronriciuez, J. R. (1979): "La colección de la casa de la condesa de Lebrija I. Terra sigillata». Studia Archaeológica, 58, Valladolid.

MarTIN-KILCHER, S. (1987): Die römischen Amphoren aus Augst und Kaiseraugst. Forschungen in August, 7/1.

OxÉ, A., y COMfort, H. (1968): Corpus Vasorum Aretinorum. A Catalogue of Signatures, Shapes and Cronology of Italian Sigillata, Bonn.

PEAcock, D. P. S. (1974): «Amphorae and the Baetican Fish Industry". The Antiquaries Journal, LIV, 232-243

Peacock, D. P. S., y Williams, D. F. (1987): Amphorae and the Roman Economy; an introductory guide, Longman, Avon.

Ponsich, M. (1988): Aceite de oliva y salazones de pescado. Factores geoeconómicos de Bética y Tingitania, Universidad Complutense de Madrid, Madrid.
Privotsi, M., y (liariana. J. F. (1987): «El taller de anforas de Torre Llauder: nuevas aportaciones». I Col.loqui d'Arqueologia Romana. El Via l'Antiguitat: Economia. Producció $i$ Comerç al Mediterrani Occidental (Badalona 1985), 199-209. Barcelona.

RI:MISAL RoI)RIGt1/. J. (1977-78): «La economia oleicola bétıca: nuevas formas de análisis». Archivo Espanol de Aryueologia, 50-51, 87-142.

Rimi:SAl. Rodriciul/, J. ( 1989$)$ : "Cuestiones en torno a la epigrafia anfórica de la Bética». Amphores romaines et histoire économique; dix ans de recherche, Actes du Colloque de Sienne (Siena. 1986), 489-503, Roma.

Rhoves, D. (1987): Hornos para ceramistas, Ceac, Barcelona.

Romero Carnicero, M. ${ }^{2} \mathrm{~V}^{\mathrm{a}}$. (1985): Numancia I. La Terra Sigillata. Excavaciones Arqueológicas en España, 146.

Ste. Croix, G. E. M. de, (1988): La lucha de clases en el mundo griego antiguo, Critica, Barcelona.

Sotomayor, M. (1969): «Hornos romanos de ánforas en Algeciras». Actas del X Congreso Nacional de Arqueologia (Mahón, 1967), 389-399, Zaragoza.

TCHERNIA, A. (1969): «Recherches sous-marines». Gallia XXVII, fasc. 2, 465-499.

TCHERNIA, A. (1989): «Encore sur les modèles économiques et les amphores). Amphores romaines et histoire économique; dix ans de recherche, Actes du Colloque de Sienne (Siena, 1986), 529. 536, Roma.

VEgAS, M. (1973): Cerámica común romana del Mediterráneo Occidental, Instituto de Arqueología y Prehistoria, Publicaciones Eventuales n. ${ }^{\circ} 22$, Universidad de Barcelona, Barcelona.

ZEvi, F. (1966): «Appunti sulle anfore romane. I. -la tavola tipologica de Dressel». Archeologia classica, vol. XVIII, fasc. 2, 208-247. 